\title{
INDIFERENÇA, SIMETRIA E PERFEIÇÃO SEGUNDO LEIBNIZ ${ }^{1}$
}

\author{
Déborah Danowski*
}

"la tempête incertaine d'une extravagante indifférence" Leibniz, Remarques sur le livre de l'origine du mal..., 19.

\begin{abstract}
"aucune chose ne se presente à nous où il n'y ait quelque difference, pour legiere qu'elle soit; et ... ou à la veuë ou à l'atouchement, il y a tousjours quelque plus qui nous attire, quoy que ce soit imperceptiblement. Pareillement qui presupposera une fisselle egalement forte par tout, il est impossible de toute impossibilité qu'elle rompe; car par où voulez-vous que la faucée commence? et de rompre par tout ensemble, il n'est pas en nature."
\end{abstract}

Montaigne, Essais, Comme nostre esprit s'empesche soy-mesmes ${ }^{2}$

RESUMO $\mathrm{Na}$ Teodicéia, Leibniz apresenta três soluções para o sofisma de Buridan, em particular, e para o problema da liberdade de indiferença, em geral. A primeira refuta a idéia de que, mesmo em uma situação de perfeito equilíbrio e total ausência de uma razão determinante, os homens (diferentemente dos animais irracionais) seriam capazes de agir. As outras duas refutam diretamente a possibilidade de haver no universo tal situação de equilíbrio e simetria perfeitos, de modo que o próprio sofisma perde seu sentido.

1 Este texto, do qual apresentei uma versão um pouco reduzida no IV Colóquio Internacional de Estudos Filosóficos do Século XVII (Curitiba, setembro de 2001), foi parcialmente escrito com apoio da CAPES. Agradeço a Renaud Barbaras, Michel Fichant e Ulysses Pinheiro a leitura e discussão acerca de diversas fases do manuscrito.

* Departamento de Filosofia, PUC-Rio.

2 Foi Luiz Alves Eva quem me chamou a atenção para este texto de Montaigne. 
ABSTRACT In the Theodicy, Leibniz presents three different solutions to the sophism of Buridan's Ass, and more generally, to the problem of the liberty of indifference. The first criticizes the idea that, even in a situation of perfect equilibrium and complete absence of a determining reason, men (as opposed to irrational animals) would be able to act. The other two deny the very possibility of perfect equilibrium and symmetry in the universe, such that this sophism looses its meaning.

Palavras-chave Leibniz, liberdade de indiferença, simetria, indiscerníveis, perfeição.

A bem conhecida distinção feita por Leibniz entre verdades de razão e verdades de fato se apóia em uma outra distinção, igualmente importante, entre dois princípios fundamentais de nossos raciocínios, o princípio de contradição e o princípio de razão suficiente. Leibniz denomina "verdades de razão" aquelas verdades (proposições) que são necessárias, e cujo oposto é impossível, ou seja, implica contradição. Isso significa que essas verdades podem ser demonstradas por meio de uma análise das noções nelas contidas em noções cada vez mais simples, até que fique imediatamente evidente a identidade entre o sujeito e o predicado da proposição. Já as "verdades de fato" são contingentes, e seu oposto, embora não seja real, permanece possível. Essa contingência, entretanto, não significa que não se possa e não se deva encontrar a razão das verdades de fato. Também aqui deve ser possível, através de uma análise, mostrar a identidade, ao menos parcial, entre o sujeito e o predicado, ou, dito de outra forma, mostrar que o conceito do predicado está contido no do sujeito da proposição. Mas essa seria uma análise infinita, acessível apenas a um entendimento também infinito, que vê, não o final da análise (já que, por causa da infinidade dos predicados incluídos em cada substância individual, essa análise não tem fim), mas a ligação entre todos os termos e a inclusão do predicado no sujeito ${ }^{3}$. Além disso, como o contrário da proposição também é possível, a razão da existência dessa verdade em lugar de seu contrário deve levar em conta, em primeiro lugar, a compossibilidade entre essa e todas as outras verdades; e, em segundo lugar, como existem infinitos conjuntos de compossíveis, essa razão depende ainda de um terceiro princípio fundamental para o sistema leibniziano: o princípio do melhor. Nosso mundo, o mundo real, é a melhor dentre as infinitas séries infinitas de existências compossíveis. De modo que a razão suficiente de qualquer verdade contingente está, em última análise, na vontade de Deus, que 
escolheu, dentre todos os mundos possíveis, concebidos sem exceção por seu entendimento infinito, o melhor. Inclinado por sua vontade soberanamente boa, e guiado por seu entendimento, que lhe mostrou, não apenas todos os possíveis, e não apenas todas as infinitas combinações ou mundos possíveis, mas também qual o melhor de todos eles, Deus, por meio de sua potência também infinita, deu existência a este mundo, deixando os outros concorrentes como meros possíveis irrealizados ${ }^{4}$.

Assim, do ponto de vista da potência divina, todos os compossíveis se equivalem, ou seja, são indiferentes (Théodicée, 174). Todos aspiram com igual direito à existência, e todos poderiam ter sido contemplados com a passagem à realidade. Por isso, se procurássemos a razão suficiente de uma verdade contingente apenas nessa potência, nunca a encontraríamos ${ }^{5}$. Por outro lado, do ponto de vista do entendimento ou sabedoria divina, nenhum compossível é igual a outro. Pois, embora todos os possíveis tendam com igual direito à existência, eles o fazem de maneira proporcional à quantidade de essência ou realidade que implicam, ou seja, a seu grau de perfeição ${ }^{6}$. Além disso, esse grau de perfeição depende diretamente da ligação de cada substância com a série inteira do universo expressa em seu conceito. Assim, cada substância, ou antes cada conceito de cada substância que compõe cada um desses universos possíveis é absolutamente único, e subordina ou está subordinado a todos os outros ${ }^{7}$, de modo que, nesse sentido, nada, nem um fio de cabelo, é indiferente a Deus. "Não se deve imaginar que qualquer acontecimento, por menor que seja, possa ser concebido como indiferente em relação à sua [de Deus] bondade e sabedoria" (id., 174). Tal é a cena que a sabedoria divina apresenta à sua vontade. E esta, que, antecedentemente, possui uma inclinação para "criar e produzir todo bem possível" (id., 116), assim como para evitar todo mal, tomados isoladamente, vê-se levada a considerar a ligação ou combinação de todos os bens e males que lhe são apresentados, e a escolher, consequentemente, a melhor combinação possível, a saber, aquela que realiza o máximo de essência com um mínimo de gasto ou de princípios (De la production originelle des choses..., ibid.). ${ }^{8}$

Ver, p.e., Théodicée, "Remarques sur le livre de 1'Origine du Mal", 14.

5 É assim que, se a necessidade que leva Deus a produzir o mundo fosse metafísica (e não apenas moral), Deus teria produzido todos os possíveis, ou nenhum. Cf. Théodicée, 201.

6 "Todos os possíveis, isto é, tudo que exprime uma essência ou realidade possíveis, tendem, com direito igual, à existência, proporcionalmente à quantidade de essência ou realidade, isto é, ao grau de perfeição que eles implicam (De la prochuction originelle des choses prise à sa racine, in Schrecker 1978: p. 85) .

7 Cf. Théodicée, 200: "A ligação e a ordem das coisas fazem com que o corpo de todo animal e de toda planta seja composto de outros animais e de outras plantas, ou de outros seres vivos e orgânicos; e que, consequentemente, haja subordinação, de modo que uma substância sirva à outra: assim sua perfeição não poderia ser igual."

8 Essa combinação, portanto, nem incluirá todos os bens a que se inclina primitivamente a vontade divina, 
Portanto, a vontade divina não apenas prefere antecedentemente os bens aos males, mas ainda, iluminada pela sabedoria divina, terá sempre uma razão suficiente determinando sua escolha final ou consequente de um objeto possível em detrimento de outros, seja esse objeto mais ou menos perfeito. É verdade que essa determinação da vontade por uma razão não a obriga por uma necessidade absoluta, matemática ou metafísica, que não tem lugar no caso das verdades contingentes, mas apenas por uma necessidade moral ou hipotética. Ou seja, moralmente falando, Deus não poderia agir de maneira diferente da maneira como agiu — pois, sendo perfeito, sempre irá querer o melhor; mas, metafisicamente falando, ele poderia ter escolhido algo diferente do melhor, e por isso sua escolha foi livre, e a realidade criada conserva sua contingência (cf. Théodicée, 234 e 228). Apesar disso, ou seja, apesar de não ser necessitada (no sentido metafísico da palavra), a ação de Deus decorre sempre de uma inclinação de sua vontade. Na fórmula de Leibniz: a razão que guia a vontade "inclina, sem necessitar".

Essa fórmula, "inclinação sem necessitação", tem dois sentidos em Leibniz ${ }^{9}$. A ausência de necessidade da escolha resultante da inclinação se explica em alguns textos (p..e., Discurso de Metafísica, 30, Teodicéia, 45 e Correspondência com Clarke $5^{\circ}$ texto de Leibniz, 8) simplesmente pelo fato de que aquilo que não é escolhido permanece possível em si mesmo (ou seja, teria sido possível, não seria contraditório, escolher outra coisa). Por outro lado, mais adiante na Teodicéia (Remarques sur le livre de l'Origine du Mal, 13-14) e em alguns outros textos, como por exemplo "Conversations sur la liberté et le destin" (in Grua p. 479), Leibniz sublinhará antes o papel da análise infinita das proposições contingentes, que, por deixar sempre um "resto" a ser explicado pela razão, não pode determinar a vontade de um modo absoluto; ou, dito de outra forma, não se pode demonstrar a necessidade da ligação entre aquele predicado e o sujeito..$^{10}$

nem excluirá todos os males. Será a melhor série possível: o máximo de bens com o mínimo de males; ou ainda, dito de outra forma, a maior variedade possível de efeitos produzidos pelo menor número de princípios. Para uma discussão da relação, em Leibniz, entre a "maximização" da perfeição ou quantidade de essência e a ordem, ver D. Rutherford 1998: 22-ss.

9 cf. Adams, 1994:34

10 Notemos, entretanto, que as duas abordagens não parecem ser mutuamente excludentes para Leibniz. Ambas ocorrem, embora em pontos diferentes, nos mesmos Ensaios de Teodicéia e também no mesmo texto da correspondência com Clarke acima citada - onde lemos um pouco adiante, no \$11: "Mostrei também que nossa vontade não segue sempre precisamente o entendimento prático, pois pode ter ou encontrar razões para suspender sua resolução até uma discussão ulterior." Ora, essa suspensão da deliberação por parte de nossa vontade é essencial para a explicação que Leibniz dá da contingência e da liberdade no texto "Verdades necessárias e verdades contingentes" (in Rauzy, pp. 339-354), baseada justamente na análise infinita das noções singulares e existenciais. Ou seja, se podemos suspender a escolha, é porque temos sempre, infinitamente, novas razões a incluir em nossa deliberação. Inversamente, no $\$ 30$ do Discurso de Metafísica, Leibniz parece recuzir o poder da vontade de suspender a deliberação a uma simples modalidade de seu poder de escolher entre alternativas: "... absolutamente 
Nos dois sentidos, é essa inclinação sem necessitação da vontade, entre outras coisas, que permite a Leibniz se afastar ao mesmo tempo daquelas doutrinas que recusam o apelo à razão e à vontade divinas como princípios de explicação da realidade (e essas doutrinas, segundo Leibniz, podem ser tão diferentes como o spinozismo, que defende uma necessidade cega e absoluta, e o epicurismo, para o qual uma declinação casual permitia a criação da ordem natural a partir do movimento vertical e perfeitamente uniforme dos átomos) e daquelas outras doutrinas que aceitavam o recurso a essa vontade, mas que erroneamente tinham a "liberdade de indiferença" ou "indiferença de equilíbrio" como uma modalidade mais ou menos perfeita da liberdade. ${ }^{11}$ Para Leibniz, a total indiferença da vontade, assim como a necessidade absoluta e como o puro acaso, é ao mesmo tempo impossível e indesejável - e isso não apenas no que diz respeito à vontade e às ações de Deus, mas também às das criaturas, racionais ou irracionais.

É bom esclarecer que estarei tomando aqui o termo "indiferença" sempre no sentido da indiferença total, vaga ou de equilíbrio. Mas Leibniz ressalva diversas vezes (p.e. em Théodicée, I § 46) que podemos falar em uma indiferença, se entendermos por ela "que nada nos necessita (i.e. que somos apenas inclinados, nos dois sentidos que acabamos de encontrar para essa palavra) em direção a uma alternativa ou à outra; mas não há jamais uma indiferença de equilíbrio, isto é, em que tudo seja perfeitamente igual dos dois lados, sem uma inclinação maior para um deles." 12

falando, [a vontade] possui uma indiferença enquanto a opomos à necessidade, e tem o poder de fazer outra coisa ou ainda de suspender inteiramente sua ação, uma e outra alternativa sendo e pemanecendo possível." Dito de outro modo, quando escolhemos entre duas alternativas, a não escolhida permanece possível; quando suspendemos a deliberação e não escolhemos nenhuma das duas, as duas permanecem possíveis, o adiamento da decisão podendo ser considerado de certa forma como uma terceira altemativa, que se tomou real.

11 A posição de Descartes no que diz respeito ao valor da indiferença para caracterizar a verdadeira liberdade não é algo simples de se deteminar. Para constatá-lo, basta comparar alguns textos, como por exemplo a quarta Meditação, a parte I \$S 37 a 41 dos Princípios; e as cartas a Mesland de 2 de maio de 1644 e de 9 de fevereiro de 1645. Ver também infra, nota 14.

12 Coerentemente, portanto (cf. nota anterior), Leibniz associa a idéia dessa indiferença (que não é a de equilíbrio) tanto ao fato de que aquilo que não é escolhido permanece possível como ao fato de que as proposições contingentes comportam uma análise infinita. Em "Vérités nécessaires et vérités contingentes" (id. p. 344), a indiferença que acompanha a liberdade é explicada pelo fato de que, embora se possa dizer com certeza que nunca escolheremos o que nos parece pior, não se pode prever que escolheremos - que nos parece o melhor dentre as duas alternativas que consideramos no presente; pois podemos adiar e suspender nosso juízo "até uma deliberação posterior, desviando a alma para outros pensamentos". Esse adiamento poderia em princípio se prolongar indefinidamente, mas não para sempre; do contrário, se não parássemos em algum ponto, ficaríamos indefinidamente incluindo novas considerações, o que nos levaria a uma inação semelhante à da indiferença de equilíbrio - cp. Nouveaux Essais, II-I-19, pp. 93-4 e II-XX-6, p. 130 (paradoxalmente, a decisão do espírito, num deteminado momento, de parar de adiar e escolher depende não apenas de seu grau de perfeição, mas também de sua limitação essencial enquanto criatura; ou seja, sua limitação faz com que ele precise adiar; mas faz ao mesmo tempo com que ele páre de adiar num certo momento, mesmo sem conhecer a totalidade da série infinita, e portanto sem que sua escolha seja necessariamente a melhor. É essa limitação que explica a escolha do pecado, que, portanto, não depende de Deus, mas da substância livre que ele criou) . 
Essa recusa da idéia de que a indiferença é uma condição compatível com o exercício de nosso livre arbítrio fica bastante clara nos Ensaios de Teodicéia, texto de 1710, particularmente naqueles parágrafos em que Leibniz analisa o sofisma conhecido na escolástica como "o asno de Buridan." Jean Buridan foi um filósofo escolástico do século XIV, e o famoso sofisma a ele atribuído esteve no centro de várias discussões em torno da questão do livre arbítrio ${ }^{13}$. Em seu Dictionnaire historique et critique (art. "Buridan”), Pierre Bayle fizera um longo comentário a ele, e é principalmente esse comentário que Leibniz tem agora em vista. O sofisma, segundo Bayle, tem duas versões. Na primeira, um asno faminto e que se encontrasse a igual distância de duas medidas de aveia seria incapaz de se determinar para um lado ou para o outro, e acabaria morrendo de fome. Na segunda versão, o asno teria tanta sede quanta fome, e estaria diante de uma medida de aveia e de um balde d'água; mas como ambos agiriam igualmente sobre suas faculdades, ele também acabaria morrendo de sede e de fome. Nos dois casos, explica Bayle, "como não teria qualquer razão para preferir um ao outro, o asno permaneceria imóvel como um pedaço de ferro entre dois ímãs de força igual".

Esse desfecho soa justificadamente absurdo, e Bayle chega a dizer que o considera "físicamente impossível". Ele não está disposto, por exemplo, ao sacrifício feito por Spinoza, que não vê qualquer problema em admitir, na Ética II (escólio da prop. XLIX), que uma pessoa que se encontrasse nessa situação de equilíbrio deixar-se-ia morrer de sede e de fome, exatamente como um asno, ou como uma mera estátua de homem. Bayle entende que, de fato, o homem dispõe de duas vias para escapar da "armadilha" do equilíbrio paralisante. A primeira é nosso livre arbítrio, que nos permite eleger uma das alternativas simplesmente pelo prazer de mostrar que "somos os senhores em nossa própria casa"; como quando dizemos: "eu quero preferir isto àquilo, porque assim me apraz fazê-lo". A segunda via é delegar a escolha ao acaso. Se um homem tivesse que decidir a qual dentre duas damas deveria dar a precedência, e se não encontrasse nelas nada que o determinasse, poderia fazê-las tirar a sorte no palitinho. Ou seja, a sorte decidiria por ele, fornecendo-lhe desse modo um remédio contra a inação a que Spinoza parecia condená-lo.

Ao longo da Teodicéia, Leibniz apresenta, grosso modo, três soluções para o sofisma de Buridan, em particular, e para o problema da liberdade de indiferença, em geral. A primeira refuta essa idéia de que, mesmo em uma 
situação de perfeito equilíbrio, ou seja, de total ausência de uma razão determinante, os homens (diferentemente dos animais irracionais) seriam capazes de agir. As outras duas refutam diretamente a possibilidade de haver uma semelhante situação de perfeito equilíbrio e simetria, de modo que o próprio sofisma perde seu sentido.

Primeiramente, é uma ilusão achar que nós alguma vez agimos sem termos sido determinados por motivos, isto é, por alguma razão ou inclinação anterior. A primeira via apontada por Bayle para escaparmos do equilíbrio é totalmente estéril. Ela se apóia em uma concepção da vontade como uma faculdade cuja essência e excelência é ser capaz de criar uma diferença lá onde não existe qualquer diferença, ou, na linguagem de Leibniz, de criar uma determinação a partir da pura indeterminação ${ }^{14}$. Mas se, frente a duas alternativas igualmente atraentes, elegemos uma delas simplesmente para exercitar nosso livre arbítrio, ou para provar que somos "donos de nós mesmos", em primeiro lugar estamos sendo movidos justamente pelo desejo de provar nossa liberdade e independência ${ }^{15}$; em segundo lugar, e mais importante, esse desejo não possui em si mesmo nada capaz de causar uma especificação, ou seja, não é suficiente para que se determine qual das alternativas será afinal escolhida para satisfazer a ele. Mesmo impulsionados por esse motivo, permaneceríamos incapacitados para fazer uma escolha, se nossa vontade não fosse determinada por outras razões e inclinações, frequentemente pequenas demais para que nos apercebamos delas. Ou então, se dizemos: "Escolhi tal coisa porque sim, porque assim me aprouve (Théodicée, 306) - como se com isso estivéssemos referindo nosso ato exclusivamente à nossa vontade, e esta a mais nada —, esse "porque me aprouve" já esconde uma inclinação em direção à alternativa escolhida. Na verdade, mesmo quando nossa vontade segue uma razão e deliberação perfeitamente distinta e consciente, esta é apenas a resultante de uma infinidade de pequenas percepções e inclinações, que podem passar desapercebidas, mas que nem por isso são menos determinantes. "Há uma infinidade de figuras e movimentos presentes

14 Leibniz analisa uma concepção semelhante no texto, que se segue à Teodicéia, em que combate as idéias de William King, Remarques sur le livre de l'Origine du Mal, publié depuis peu en Angleterre. A idéia se encontrava já no filósofo-teólogo árabe Al-Ghazali (1058-1111), e também em alguns escolásticos cf. N. Rescher, q. cit. pp. 146-146-7. É também a concepção de Descartes que, na carta a Mesland de 9 de fevereiro de 1645, identifica a indiferença a essa "faculdade positiva [da vondade] de se determinar em direção a um ou outro dentre dois contrários". Embora aqui a indiferença não fique mais limitada (como na quarta Meditação) às situações em que não somos impelidos mais para um lado que para outro, caracterizando antes o poder de, mesmo quando fortemente levados por razões claras e distintas a uma alternativa, escolher a altemativa contrária, ainda assim a idéia subjacente é de que a vontade é capaz de criar sua própria deteminação. Note-se entretanto a distinção que Descartes faz, nessa mesma carta, entre o fato de que, uma vez fortemente impelidos a um dos lados, não podemos, moralmente falando, escolher - partido contrário, e o fato de que, absolutamente falando, nós o podemos.

15 Cf. também Nouveaux Essais, II-XXI-25, p. 143. 
e passados que entram na causa eficiente de meu ato presente de escrever, e há uma infinidade de pequenas inclinações e disposições de minha alma, presentes e passadas, que entram na causa final" (Monadologie, 36) ${ }^{16}$.

É pelo mesmo motivo que a segunda via de Bayle também não resolve o sofisma de Buridan. Delegar a escolha à sorte ou acaso não deixa de ser um reconhecimento de nossa incapacidade de fazer essa escolha quando nenhuma razão nos inclina mais para um lado que para outro. E seria inútil afirmar que não é a sorte que decide, que nós mesmos decidimos por meio dela. Pois nesse caso, dirá Leibniz, "o próprio homem não está mais em equilíbrio, porque a sorte não está, e o homem se vinculou a ela" (Théodicée, 307). A sorte não está em equilíbrio porque ela também é determinada por razões. "Na natureza há sempre razões que são causa do que acontece por acaso ou pela sorte" (idem); apenas, essas razões são tão complexas ou imperceptíveis que geram a aparência do acaso, isto é, de que alguma coisa acontece sem ter sido determinada por nenhuma causa.

Esses argumentos contra a idéia de uma liberdade de indiferença não dependem apenas da constatação, na experiência, de que nunca praticamos uma ação que não tenha tido um motivo, por mais imperceptível que fosse; e de que, inversamente, numa situação perfeitamente equilibrada, não há escolha nem ação, de modo que qualquer artifício para sair dessa paralisia só tem efeito ao quebrar esse mesmo equilíbrio, ou seja, ao produzir uma inclinação. A indiferença da vontade e o acaso, considerados como causas, não são apenas inexistentes de fato, eles são quimeras, diz Leibniz, supõem situações impossíveis, que nunca existiram e nunca poderão existir, porque contrariam o grande princípio da razão determinante ou razão suficiente. Esse princípio diz que nada se faz sem uma causa ou razão suficiente. E assim como um corpo só pode ser posto em movimento pelo movimento de um outro corpo que o impulsiona, assim também a alma, para agir, tem que ter sido determinada por alguma causa ou razão ${ }^{17}$. É verdade que a alma, diferentemente da matéria, é ativa por si própria ${ }^{18}$ - e é isso que garante sua perfeita espontaneidade, e consequentemente sua liberdade. Mas isso não significa que ela

16 Ver também Théodicée, 46 e 305.

17 Théodicée, Remarques sur le livre de l'Origine du Mal, 3 e \$ 46: "Tudo que acabamos de dizer está perfeitamente de acordo com a máximas dos filósofos, que ensinam que uma causa não poderia agir sem ter uma disposição para a ação; e é essa disposição que contém uma pré-determinação, quer o agente a tenha recebido de fora, quer a tenha tido em virtude de sua própria constituição anterior."

$18 \mathrm{Na}$ verdade, também o movimento de um corpo é só aparentemente causado por um corpo externo: "Quando os corpos ricocheteiam após o choque, é pelo efeito da força elástica; donde se segue que, na realidade, o movimento que eles parecem receber do choque é um movimento que pertence a eles, que eles tiram de sua própria força, força à qual o impulso extemo só fornece a ocasião de agir, e por assim dizer uma determinação." (Gerhardt, thil. vol. IV, 469-470 - citado por Moreau 1987: p. 153) . Cf. ainda "De la nature en elle-même" \$ 14, in Schrecker, p. 109. 
possua essa espécie de faculdade mágica capaz de criar uma determinação a partir do nada e da completa indeterminação. Ao contrário, se sua ação é espontânea é porque ela encontra em si mesma, em seus estados precedentes, e já em sua natureza ideal anterior à existência, as razões de sua determinação, e consequentemente as razões de suas ações livres, harmonizadas desde a eternidade com tudo que a rodeará (Théodicée, 323). ${ }^{19}$

Querer que uma determinação venha de uma plena indiferença absolutamente indeterminada é querer que ela venha naturalmente do nada. Supõe-se que Deus não concede essa determinação; portanto, ela não tem origem na alma, nem no corpo, nem nas circunstâncias, já que se supõe que tudo é indeterminado. E ei-la entretanto que aparece e que existe, sem preparação, sem que nada leve a ela, sem que um anjo, sem que Deus mesmo possa ver ou fazer ver como ela existe. Isso não é apenas sair do nada, mas sair do nada por si mesmo. (Théodicée, 320)

Na verdade, a noção de uma vontade isenta de motivos, ou como capaz de se sobrepor ao equilíbrio entre suas diversas inclinações, já é uma noção auto-contraditória. Pois essas inclinações e motivos não estão fora da vontade, como pesos que fazem uma balança se inclinar (cf. Correspondance Leibniz-Clarke, 5• texto de Leibniz, 15). Eles constituem a própria vontade, que se inclina, portanto, espontaneamente e por sua própria natureza e disposições. "Uma mera vontade sem motivo (a mere will) é uma ficção, não apenas contrária à perfeição de Deus, mas também quimérica e contraditória, inconsistente com a definição da vontade" (idem, $4^{\circ}$ texto de Leibniz, 2). Por isso, aos olhos de Leibniz, é claro o parentesco da compreensão errônea do livrearbítrio como fundado sobre uma total indiferença com a noção auto-contraditória do acaso como algo capaz de causar verdadeiramente alguma coisa. "Todos os sábios concordam", diz ele, que o acaso não é uma coisa real mas sim aparente, um termo que apenas esconde nossa ignorância das causas (Théodicée, 303). Mas se pudéssemos escolher sem que houvesse nada que nos levasse a escolher algo determinado, se a vontade fosse essa faculdade pura, capaz de criar uma diferença onde não há absolutamente qualquer diferença, então o acaso, o puro acaso, "sem razão determinante, aparente ou oculta", seria algo real. E isso é ao mesmo tempo falso, absurdo e ridículo; tão ridículo quanto aquela pequena declinação atômica introduzida por Epicuro para escapar da necessidade e do pleno determinismo a que seu sistema

19 Sobre a relação entre as noções de espontaneidade, liberdade e contingência, bem como sobre a maneira como o conceito leibniziano de substância individual toma, não apenas compatível, mas indissociável o vínculo entre essas noções e a de determinação, ver L.H. Lopes dos Santos 1998. Para uma leitura diferente, mais centrada no conceito de análise infinita e no modo de conexão entre os predicados, ver, no presente volume, U. Pinheiro, "Contingência e análise infinita em Leibniz". 
parecia condenar o mundo ${ }^{20}$. Ora, essa declinação ou clinamen não era senão uma espécie de livre arbítrio atômico, ele mesmo inexplicável, mas supostamente capaz de desviar os átomos materiais de sua inexorável queda vertical, ao mesmo tempo em que livrava o homem de sua submissão ao destino (idem, 321). Mas, com isso, na avaliação de Leibniz, Epicuro não resolvia, apenas mudava a dificuldade de lugar.

Vemos, assim (retornando ao sofisma de Buridan), que aquelas duas vias propostas por Bayle no fundo se equivalem, e não poderiam ser aceitas por Leibniz. A vontade que triunfa sobre a vaga e plena indiferença já é por si mesma uma espécie de acaso (ou vice-versa), e este, por sua vez, será uma noção completamente absurda se não o quisermos reduzir à nossa mera ignorância das causas determinantes. Ou seja, ou a vontade mesma quebra o equilíbrio, isto é, produz uma determinação a partir da pura indeterminação (mas isso violaria o princípio da razão suficiente), ou escapa da indiferença e do equilíbrio apelando para o acaso, que por sua vez, entendido corretamente, situa-nos longe de qualquer equilíbrio. Em outras palavras, parece que não há saída: se o equilíbrio é rigorosamente mantido, se, como acontece na situação proposta por Buridan, não há uma razão que nos incline mais para um lado que para outro, então Spinoza está certo: a ação é de fato impossível; e, homens ou asnos, acabaríamos por morrer de fome ou de sede.

Mas, ao mesmo tempo, Leibniz, como Bayle, não quer aceitar esse desfecho. Sem poder abrir mão, seja da completa determinação de todas as substâncias, seja da liberdade e da contingência, ele enxergará uma solução onde nem Spinoza nem Bayle enxergaram. No fundo, diz ele, a discussão é sobre o impossível. A armadilha do equilíbrio paralisante simplesmente não existe, porque não há, não pode existir um equilíbrio perfeito no universo.

Para haver uma situação de equilíbrio teríamos que supor duas coisas: em primeiro lugar, um ponto fixo de referência ou um ponto de vista em relação ao qual se possa dizer que há duas ou mais alternativas, dois ou mais lados equilibrados; ou seja, temos que definir "lados" em relação a um sujeito. Em segundo lugar, temos que supor uma simetria ou igualdade, seja entre dois ou mais objetos quaisquer, tomados isoladamente de cada um desses lados ou alternativas, seja entre os valores que esses objetos têm para o sujeito em questão. As duas versões do sofisma de Buridan contemplam precisamente essas duas possibilidades: na primeira versão, o asno faminto tem, de cada lado, uma medida de aveia que lhe parece exatamente igual à outra. $\mathrm{Na}$ segunda versão, o asno, com tanta sede quanta fome tem, dos dois lados, objetos diferentes (uma medida de aveia e um balde d'água), mas que satisfa- 
riam de maneira igual a cada um de seus apetites separadamente. Vejamos a resposta de Leibniz:

\begin{abstract}
“... o caso do asno de Buridan, entre dois prados e igualmente levado a um e a outro, é uma ficção que não poderia ocorrer no universo, na ordem da natureza [...] no fundo, a questão é sobre o impossível, a menos que Deus produza a coisa propositalmente [exprès]. Pois o universo não poderia ser bipartido por um plano vertical que passasse pelo meio do asno, cortando-o longitudinalmente de forma que tudo fosse igual e semelhante de um lado e de outro, ao modo de uma elipse e de todas as figuras planas do tipo daquelas que denomino anfidestras, e que podem ser assim bipartidas por alguma linha reta que passe por seu centro: pois nem as partes do universo, nem as vísceras do animal são semelhantes ou estão situadas igualmente dos dois lados desse plano vertical" (Théodicée, 49).
\end{abstract}

Em primeiro lugar, notemos que Leibniz não considera aqui a segunda versão do sofisma, que entretanto havia sido mencionada por Bayle. Ele descreve o asno como parado entre dois objetos iguais: dois prados, ou duas medidas de aveia. E quando propõe sua solução, modifica também a situação representada na primeira versão: a simetria que ele imagina (que imagina não poder existir) não é apenas entre esses dois objetos, mas entre os dois lados do universo. Assim, somos levados a entender a indiferença da vontade como dependendo necessariamente de uma perfeita e total simetria de todo o universo. Além disso, como se para reforçar essa idéia, o exemplo geométrico escolhido é o daquelas figuras que Leibniz define como "anfidestras" (ou seja, figuras com um alto grau de simetria, que contêm um ponto tal que toda reta que passa por esse ponto divide a figura em duas partes de áreas iguais), de modo que esse universo simétrico se multiplica imediatamente em, não apenas duas, mas infinitas partes equivalentes (de áreas iguais), ou seja, tantas partes quantas linhas podemos passar pelo ponto em questão.

É interessante que Spinoza, quando comenta o sofisma, diga que o equilíbrio que gera a inação depende do isolamento dos dois objetos possíveis da escolha em relação ao resto da experiência: "Concordo inteiramente que um homem situado em tal equilíbrio (i.e. que não percebe nada além da sede e da fome, tal alimento e tal bebida igualmente distantes dele) morrerá de fome e de sede" (Ética II, escólio da prop. XLIX, pp. 409-10, meu grifo). Leibniz poderia ter afirmado a impossibilidade do equilíbrio perfeito tomando também como parâmetro apenas dois objetos isolados. Ele dispunha de um instrumento mais que suficiente para isso: seu princípio da identidade dos indiscerníveis. Esse princípio diz que não pode haver na natureza duas coisas individuais que difiram apenas numericamente ${ }^{21}$. Se elas são diferentes, deve 
haver (pelo princípio da razão suficiente) uma razão para essa diferença. Ora, como todas as relações que um objeto pode manter com outro já estão contidas desde sempre no próprio conceito desse objeto (em outras palavras, como todo predicado está contido no sujeito), a razão que diferencia dois objetos tem que ser interna à essência de cada um: “... não há denominações puramente extrínsecas que não tenham um fundamento também na própria coisa denominada. Pois é preciso que a noção do sujeito denominado envolva a noção do predicado" (Principes logico-métaphysiques, p. 461). Dito de outra forma, se duas substâncias têm exatamente os mesmos predicados, sem exceção, então elas são também numericamente idênticas, isto é, são uma e não duas substâncias. Assim, ainda que (por absurdo) tivéssemos duas substâncias iguais, o simples fato de, por exemplo, uma se localizar à esquerda e a outra à direita do sujeito em questão implicaria a existência de relações (espaciais) que, embora aparentemente exteriores às duas substâncias, teriam que estar expressas em propriedades internas a cada uma delas - e essas substâncias seriam, portanto, numérica e essencialmente diferentes, o que já constituiria uma razão suficiente para inclinar a vontade. ${ }^{22}$

Entretanto, no fundo, o próprio princípio dos indiscerníveis depende, no sistema leibniziano, da ligação harmônica de todas as substâncias umas com as outras. “... não há denominação puramente extrínseca (denominatio pure extrinseca), por causa da conexão real de todas as coisas" (Nouveaux Essais, II-XXV § 5, p. 177). ${ }^{23}$ Se nenhuma relação pode ser meramente extrínseca,

notions et des vérités, p. 460. Rauzy considera que esse texto foi composto em 1689. Na edição de Loenker (que o localiza entre 1680 e 1684), o texto recebeu o título de "First Truths" (p. 268). Não confundi-lo, portanto, com o texto publicado nessa mesma edição de Rauzy como "Sur les vérités premières" (pp. 446-448).

22 Como o presente texto trata do problema da simetria apoiando-se sobretudo na resposta de Leibniz ao sofisma de Buridan, tal como ele se encontra na Teodicéia, limitamo-nos aqui à análise da simetria espacial. Mesmo no que diz respeito à possibilidade de adiar uma decisão, trata-se antes de mostrar a impossibilidade de um equilíbrio perfeito em um momento preciso da vida do sujeito. Seria necessário, entretanto, refazer toda essa análise levando em consideração a impossibilidade de uma simetria temporal, ou seja, de uma repetição dos acontecimentos ou substâncias, tanto do ponto de vista dos sujeitos particulares como na perspectiva mais ampla da história. Sobre essa questão, ver os textos de Leibniz publicados por M. Fichant em 1991 sob o título de De l'Horizon de la Doctrine Humaine: Apokatastasis pantwn (La Restitution Universelle), assim como o posfácio deste último, "Plus ultra". Encontramos ali a mesma oposição entre um ponto de vista ideal ou abstrato e um ponto de vista concreto ou efetivo. A impossibilidade de uma simetria temporal é analisada também, embora mais rapidamente e a partir de outra perspectiva (a da noção do próprio tempo, e não das substâncias que existem no tempo), por Breger (1989: 34-5), quando este analisa a oposição de Leibniz à noção de um tempo (como de um espaço) absoluto: como o tempo não é senão uma certa relação entre acontecimentos, se Deus tivesse criado o universo em um momento posterior ou anterior ao momento em que efetivamente o criou, os dois universos (que apresentariam então uma simetria de translação, cf. Weil 1980, fig. 24) seriam indiferenciáveis. Entretanto, isso violaria o princípio dos indiscerníveis, assim como o da razão suficiente (pois Deus não teria tido uma razão suficiente para escolher um momento preciso como o momento da criação) .

23 "Philalèthe: Pode haver ... uma mudança de relação sem que ocorra qualquer mudança no sujeito. Titius, que hoje considero como pai, deixa de sê-lo amanhã, sem que haja nenhuma mudança nele, apenas porque seu filho morre. Théophile: Pode-se dizer isso no que diz respeito às coisas que percebemos; 
isto é, se toda relação está expressa no interior da substância, é porque esta contém uma infinidade, não apenas de propriedades, mas de percepções; ou, dito de outra forma, porque exprime, em sua unidade e de seu próprio ponto de vista, todas as outras infinitas substâncias que compõem com ela o universo real. Rigorosamente falando, portanto, seria impossível isolar (como faz Spinoza) dois objetos do resto; a simetria perfeita de dois objetos quaisquer dependeria necessariamente da simetria de todo o mundo que eles representam, ainda que obscuramente. Tudo isso parece estar condensado na imagem utilizada por Leibniz para refutar a indiferença de equilíbrio. Tomada de maneira abstrata, uma figura geométrica, formada de unidades homogêneas, pode ser considerada bilateralmente simétrica ou mesmo "anfidestra" (ou, se quisermos, duas ou mais figuras geométricas podem ser consideradas idênticas); mas isso só é possível porque se trata de uma abstração matemática, em que se consideram apenas noções incompletas das coisas, privilegiando-se algumas propriedades isoladas e omitindo-se suas relações com todas as outras ${ }^{24}$. Ao contrário, se inseríssemos essa mesma figura, não mais em um espaço geométrico e ideal, mas em uma extensão concreta e real, ou seja, se considerássemos os indivíduos completos e todas as infinitas relações neles contidas (se fizéssemos o plano vertical cortar vísceras e universo), então não haveria mais simetria possível.

As partes do tempo e do espaço consideradas em si mesmas são coisas ideais, e assim se assemelham perfeitamente umas às outras como duas unidades abstratas. Mas não é o que se passa com duas unidades concretas, ou com dois momentos efetivos, ou dois espaços preenchidos, quer dizer verdadeiramente atuais (Correspondance Leibniz-Clarke, $5^{\mathrm{o}}$ texto de Leibniz, 27).

Em suma, a própria indiferença de equilíbrio é uma noção incompleta ${ }^{25}$. Mesmo que não nos apercebamos disso, ao considerar dois possíveis objetos de nossa vontade estamos na verdade percebendo toda a série de substâncias expressas mais ou menos obscuramente por cada um desses objetos. Estamos percebendo a totalidade dos dois mundos possíveis distintos que se tornariam reais caso escolhêssemos uma ou outra alternativa.

mas, no rigor metafísico, a verdade é que não há denominação puramente extrínseca..., por causa da conexão real de todas as coisas".

24 Cf. J. Moreau q. cit: 202-204; M. Serres 1990: p. 806 nota 3: "Existe um espaço homogêneo para a geometria, um espaço diferenciado para a física; o primeiro é imaginário como a indiferença, o segundo é bem fundado, como a inclinação." No texto "De la nature en elle-même", de 1698, embora Leibniz não se refira especificamente à noção de simetria, fica bastante claro como ela é indissociável da concepção cartesiana da matéria como pura extensão geométrica - concepção contrária à natureza e à ordem das coisas, pois "não há jamais, em lugar algum, uma similitude perfeita" (in Schrecker, p. 108) .

25 Cf. carta a Amauld, 4/14 julho 1686, p. 122: "Uma perfeita indiferença é uma suposição quimérica ou incompleta." 
Por isso mesmo, um adiamento da decisão, a cuja possibilidade Leibniz já se referia em seu texto "Verdades necessárias e verdades contingentes" como caracterizando a contingência, e com ela um outro tipo de indiferença, de nossas ações livres (cf. acima, notas 10 e 11), tampouco nos permitiria sair de um equilíbrio perfeito. Ao contrário, se podemos suspender e adiar nossa decisão é porque existe um motivo que nos inclina a isso, mais que a realizar imediatamente a escolha. A inação que domina o asno de Buridan (ou que o dominaria, se fosse possível o perfeito equilíbrio) não se dá porque ele estaria protelando demasiadamente sua decisão, buscando levar em consideração sempre outras alternativas. Ela ocorre por ele ser prisioneiro daquela alternativa estreita e isolada que se lhe apresenta no presente, e não poder sair desse embaraço. $\mathrm{O}$ adiamento, ao contrário, depende da possibilidade de se introduzir sempre mais um termo na alternativa. Ora, justamente, essa introdução é sempre possível, infinitamente.

Se ainda quisermos falar de equilíbrio, portanto, a única possibilidade que parece restar é que os dois objetos, embora diferentes, tivessem para nós o mesmo valor, ou então que os dois mundos alternativos definidos por esses objetos contivessem a mesma soma de bens e males e por isso o mesmo valor global, ou seja, fossem igualmente atraentes ou repulsivos. Chegamos, assim, à segunda versão do sofisma de Buridan.

Embora Leibniz não comente diretamente essa versão, podemos arriscar algumas hipóteses. O que significa dizer que dois objetos teriam para nós o mesmo valor? Significa, por exemplo, que se o asno tem tanta sede quanta fome, seria igualmente atraído por um balde d'água e por uma medida de aveia. Bayle descrevia essa possibilidade como uma situação em que a fome e a sede pressionariam [préssaient] o asno de maneira igual, ao mesmo tempo em que ele teria diante de si uma medida de aveia e um balde d'água agindo com a mesma força sobre seus órgãos (Dictionnaire, idem). Entretanto, a refutação por Leibniz da possibilidade de uma simetria perfeita não se aplicava apenas aos objetos, mas também aos sujeitos; o plano vertical por ele imaginado não cortava só o universo, cortava o asno também. Ou seja, a fome e a sede só podem parecer exercer a mesma pressão se construirmos com elas uma espécie de noção incompleta, abstraindo-as de suas relações com todo o restante da realidade em que estão inseridas. $\mathrm{O}$ mesmo raciocínio se aplica se imaginarmos uma situação um pouco diferente. Suponhamos que um homem sinta apenas uma sede muito forte, e que tenha diante de si dois copos d'água, de mesma forma e tamanho, mas de cores diferentes. Ele bem poderia fazer uma abstração, e raciocinar que, embora os dois objetos sejam diferentes, eles se equivalem pelas propriedades relevantes para aquela situação, ou seja, são igualmente bons para satisfazer sua sede. Entretanto, mais uma vez, essa 
situação só poderia se dar idealmente, pois, na realidade, fora desse espaço abstrato, a própria sede não pode ser isolada de todas as outras infinitas percepções e inclinações, de modo que há muito mais razões, além da sede, que determinam a vontade desse homem para o copo de uma certa cor ao invés do outro. Mesmo a cor sendo uma qualidade supérflua no que diz respeito à sede, ela não é supérflua para pelo menos alguma das infinitas pequenas percepções que acompanham essa percepção mais distinta que é a sede. "Embora nem sempre eu veja a razão de uma inclinação que me faz escolher entre duas alternativas que parecem iguais, sempre haverá alguma impressão que nos determina, ainda que seja imperceptivel" (Teod. § 305, meu grifo).

Mas se, no que diz respeito aos valores de dois objetos, não podemos proceder a esse isolamento, será que não podemos ao contrário fazer uma avaliação das totalidades respectivas das duas experiências alternativas, e não poderia ser o caso então que essas totalidades tivessem o mesmo valor, isto é, que as somas de bens e males implicados por cada alternativa sejam iguais? A solução dessa questão ficará mais clara se abandonarmos por um momento o ponto de vista humano, e considerarmos o ponto de vista divino (embora, rigorosamente falando, Deus não tenha um ponto de vista, já que concebe em seu entendimento a totalidade dos pontos de vista possíveis). Ao mesmo tempo, ao contrário do que fizemos anteriormente, devemos aqui partir já da consideração do mundo como um todo, para finalmente chegarmos aos objetos, ações e acontecimentos individuais que constituem esse todo. Ora, se dois ou mais mundos possíveis são indiferentes a Deus, ou seja, se os dois mundos alternativos, além de igualmente possíveis, são igualmente bons ou maus, não há uma razão suficiente para a escolha de um deles ao invés do outro, e por isso Deus não poderia decretar a criação de nenhum, já que seria contrário à sua sabedoria e perfeição agir sem uma razão. Se Deus criou este mundo, portanto, podemos concluir que seu valor e seu grau de perfeição são diferentes dos de qualquer outro que pudesse ter criado.

Ora, quando Deus viu em seu entendimento a totalidade das substâncias que decidiu criar, viu também que qualquer modificação nessa série, por menor que fosse (e mesmo que fosse por exemplo a troca singular de um mal por um bem, ou de um bem menor por um bem maior), traria consigo um mundo inteiramente (infinitamente) distinto, e necessariamente menos perfeito que nosso mundo real. No que diz respeito às ações humanas, isso significa que nenhuma alternativa que se apresente à nossa vontade pode ser moralmente indiscernível de outra, já que cada alternativa implica um mundo distinto. Resta saber se, como criaturas essencialmente limitadas que somos, não podemos nos enganar quanto aos valores dessas alternativas, tomando como indiscerníveis mundos possíveis que na verdade não o são. Afinal, não é jus- 
tamente essa defasagem entre o ser e o parecer que explica a má escolha, e com ela o pecado? Suspeito que a resposta a essa pergunta já tenha que ter sido dada juntamente com as soluções de Leibniz para a primeira versão do sofisma. Pois se nossa incapacidade de ver nitidamente a totalidade infinita implicada por cada alternativa fosse suficiente para que de fato nossa vontade ficasse em equilíbrio entre as duas, também ficaríamos em equilíbrio e imóveis entre dois objetos que apenas nos parecessem iguais quando tomados isoladamente dessa totalidade. Vimos que aquilo que faz com que dois objetos isolados não possam ser idênticos é que eles na verdade não são isolados, ou seja, que cada um deles possui infinitos predicados, que têm ligação com todos os outros objetos do universo, ou seja, da totalidade. A inexistência real da simetria, seja entre dois objetos seja entre dois mundos alternativos, pode não impedir nossa apercepção confusa ou incompleta desses objetos ou mundos, e nossa representação deles como sendo iguais ou de mesmo valor para nós, mas não poderia impedir que nossa vontade continue sendo determinada, em maior ou menor grau, por todas as infinitas percepções "inapercebidas", presentes em nossa alma. Como dizíamos logo no início, a vontade que nos determina é, na maioria das vezes, apenas a resultante de uma infinidade de pequenas vontades e inclinações, que raramente percebemos.

Podemos portanto concluir que, também de nosso ponto de vista (isto é, da perspectiva das substâncias livres realmente escolhidas por Deus e tornadas reais, cujas ações fazem parte do mundo por ele escolhido, e que é o melhor de todos), não apenas não há duas coisas essencialmente iguais, como não há nenhuma opção cujo valor moral seja indiscernível do de outra. E isso nos leva ainda a concluir que, no fundo, qualquer diferença entre objetos, ações ou propriedades compossíveis com nosso mundo real mas incompatíveis entre si (i.e. compossíveis, embora não simultaneamente ${ }^{26}$ ) - em suma, qualquer diferença entre objetos entre os quais se tenha que escolher - , corresponde a uma diferença em seus graus de perfeição. Quando duas coisas são incompatíveis, se Deus tem uma razão suficiente para escolher entre elas é porque o mundo em que uma existe é melhor, e portanto mais perfeito, que o mundo em que a outra existiria. Como, então, supor que elas possam ser igualmente perfeitas, se implicam - e portanto exprimem, isto é, contêm mundos diferentemente perfeitos? De maneira semelhante, quando duas coisas incompatíveis existem em um mesmo mundo, há uma ordem temporal determinada entre elas; e se essa ordem existe é porque uma é mais perfeita que a outra, a saber, a posterior é mais perfeita que a anterior. Do contrário, se 
fossem igualmente perfeitas, nenhuma delas existiria: "Quando duas coisas incompatíveis são igualmente boas e, tanto em si mesmas como por sua combinação com outras, uma não tem qualquer vantagem sobre a outra, Deus não produzirá nenhuma delas" (Correspondance Leibniz-Clarke, $4^{\circ}$ texto de Leibniz, 19); e, inversamente: "Se dois incompatíveis existem, então eles diferem temporalmente, e aquele que é anterior por natureza (ou posterior) é anterior (ou posterior) no tempo" (VE 330. Citado por Rauzy, ibid., p. 40).

Essas últimas considerações talvez nos esclareçam sobre como compreender aquela que anunciamos como a terceira solução de Leibniz ao sofisma de Buridan, mas que (como não vem diretamente a propósito do sofisma) seria mais exatamente caracterizada como uma segunda ordem de razões que Leibniz nos apresenta para demonstrar a impossibilidade da existência de um equilíbrio e simetria perfeitos no universo. Ela aparece também na primeira parte da Teodicéia, mas alguns parágrafos antes da análise do sofisma (§ 35):

Não se deve imaginar que nossa liberdade consiste em uma indeterminação ou uma indiferença de equilíbrio, como se precisássemos estar inclinados igualmente para o lado do sim e do não, e para diferentes partidos, quando há vários a tomar. Esse equilíbrio em todos os sentidos é impossível; pois mesmo que fôssemos igualmente levados a A, B e C, não poderíamos ser igualmente levados a A e não-A.

Antes de pensarmos sobre a especificidade dessa argumentação, notemos que ela tem uma importante semelhança em relação à anterior, representada pela imagem do plano vertical: aqui também Leibniz nos leva a estender a simetria pontual a uma simetria generalizada, que compreende todo o universo. Neste caso, entretanto, o que é generalizado não é mais uma simetria entre objetos, seres ou partes homogêneas ou mesmo idênticas, mas entre as inclinações, ou as maneiras como o espírito se comporta em relação a partes contraditórias do universo. O seguinte trecho de "Verdades necessárias e verdades contingentes" deixará isso mais claro: é impossível (dizia então Leibniz) haver uma "indiferença metafísica total, em que o espírito se comporta exatamente da mesma maneira em relação a um e a outro dos contraditórios e em que, portanto, alguma coisa está, por assim dizer, em equilíbrio com a natureza inteira..." (op. cit., p. 345). O que Leibniz parece estar pretendendo fazer aqui, sobretudo no $\S 35$ da Teodicéia, é fornecer uma prova lógica de que um equilíbrio entre diferentes objetos de escolha, quaisquer que sejam eles, é impossível. Para isso, ele precisa estabelecer relações negativas entre os termos positivos, o que faz ao tratar as diferentes alternativas que se apresentam ao sujeito como contraditórias umas em relação às outras. Assim, A e B (digamos, uma medida de aveia e um balde d'água) não são termos necessariamente contraditórios em si mesmos, mas se a situação do sujeito faz com 
que ele deva escolher entre os dois, então B é necessariamente não-A e viceversa. Podemos pensar que esse raciocínio se aplica a todas as situações em que temos que fazer uma escolha. Mas, dito isso, como entender que não possamos ser igualmente levados a A e não-A? Leibniz não nos dá, nesses dois textos, nenhuma indicação de por que deva ser assim, e a única maneira que vejo de responder a essa questão é recorrer à definição de perfeição que mencionei há pouco: A e não-A são, senão incompossíveis, ao menos incompatíveis (o asno pode ter tanto a água como a aveia, mas não os dois ao mesmo tempo); e, se são incompossíveis ou incompatíveis, então necessariamente existe entre eles uma diferença nos graus de perfeição - caso contrário, Deus não teria tido uma razão para escolher a realização de um deles ao invés ou antes do outro. Somente dois seres compatíveis podem ser igualmente perfeitos ${ }^{27}$. Assim, glosando o texto que citamos acima: podemos (logicamente falando) ser igualmente inclinados para $\mathrm{A}, \mathrm{B}$ e $\mathrm{C}$; mas se reduzimos $\mathrm{B}$ e C a não-A, então não podemos (moralmente falando) ser igualmente inclinados aos três.

Um último ponto. Poder-se-ia pensar que, como nada impede que substâncias de um mesmo mundo sejam igualmente perfeitas (a saber, desde que não haja incompatibilidade entre elas), Leibniz não precisaria ter concebido o melhor dos mundos possíveis como um mundo que reúne bens e males em uma proporção ótima. $\mathrm{O}$ melhor mundo parece ser antes aquele composto exclusivamente de seres perfeitos, e por isso um mundo que só contém bens. Para refutarmos essa objeção, devemos entender que é a mesma ilusão que está por trás da idéia de que a verdadeira liberdade depende de uma indiferença de equilíbrio e da idéia, que Leibniz também combate, de que o melhor mundo possível deveria ser um mundo formado exclusivamente de substâncias perfeitas. De fato, se a liberdade de indiferença parece a alguns ser a única verdadeira liberdade, não é apenas porque, nessa situação de indiferença em que se encontra a vontade, não há "qualquer razão de se determinar, anterior à determinação, nem naquele que escolhe nem no objeto", mas também porque assim "não elegemos o que agrada; ao contrário, elegendo sem motivo, fazemos com que aquilo que elegemos agrade" (Théodicée, Sur l'origine du mal, 1). Ou seja, segundo essa hipótese, a vontade não é determinada pelo bem do objeto que escolhe; sem ver nos objetos qualquer razão de determinação, ela mesma cria essa razão, atribuindo um certo grau de bondade ao objeto da escolha, e fazendo assim com que ele nos agrade.

27 A menos que tomemos "perfeição" no sentido de "máximo de compossibilidade", definição que tem como consequência que todos os seres de um mundo possível serão igualmente (mas nunca absolutamente) perfeitos. Cf. Rauzy, q. cit, p. 43. 
Mas, nesse caso, pergunta Leibniz, o que impediria a vontade de atribuir aos objetos sempre o grau máximo de bondade, "24 quilates de bondade"? O que nos impediria de "transformar tudo em ouro pelo toque dessa faculdade mágica"? (idem, 18, 3). Se tudo é indeterminado, de onde tiraríamos a razão de um limite? Não é à toa que isso nos lembra um conto de fadas, como diz Leibniz; um mau conto de fadas, poderíamos acrescentar. É um engano pensar que um mundo composto só de seres perfeitos é o mundo mais perfeito. Em primeiro lugar, porque isso seria impossível. Se todas as substâncias criadas fossem absolutamente perfeitas, elas seriam iguais, o que contraria o princípio da identidade dos indiscerníveis, além de contradizer a noção mesma de perfeição. De fato, como todas as substâncias representam todas as outras (todo o universo), a única coisa que as diferencia é o fato de que cada uma o faz de seu próprio ponto de vista, ou seja, percebe mais ou menos distintamente uma certa região do real $^{28}$. Mas uma substância perfeita conteria apenas percepções distintas, e em nada se diferenciaria de outras substâncias perfeitas, visto que cada uma exprimiria todas as outras exatamente da mesma maneira. E, novamente, não haveria uma razão que explicasse por que umas não são as outras. ${ }^{29}$ Além disso, para que uma substância contenha apenas percepções distintas, seria preciso que nada limitasse sua perfeição ${ }^{30}$. Ora, a própria diversidade implica a existência de relações entre aquilo que é diverso, relações estas que são representadas internamente por percepções mais ou menos distintas ou confusas, conforme o grau de perfeição ou imperfeição da substância, ou seja, conforme a substância esteja agindo ou apenas sofrendo a ação das outras. "Diz-se que a criatura age fora dela enquanto tem perfeição, e sofre a ação de outra enquanto é imperfeita. Assim, atribui-se a ação à mônada enquanto ela possui percepções distintas, e a paixão enquanto possui percepções confusas." (Monadologie, 49). Se uma substância criada só tivesse percepções distintas, ela seria puramente ativa; mas sobre quê agiria ela se todas as outras substâncias criadas fossem também puramente ati-

28 Cf. carta a Amauld de 30 de abril de 1687 (in Discours de Métaphysique et Correspondance avec Arnaud, G. Leroy. Paris: J. Vrin., p. 159) : a alma exprime mais distintamente o que pertence a seu corpo, pois "não poderia exprimir igualmente todas as coisas; do contrário, não haveria distinção entre as almas".

29 Por isso, sem uma razão suficiente, Deus não teria criado nenhuma delas. Um raciocínio semelhante explica por que não poderia haver sempre um mundo mais perfeito que outro, infinitamente: se não houvesse o mundo mais perfeito possível, Deus tampouco teria criado nenhum. Cf. Théodicée, 196.

30 Discours de Métaphysique, 15: "a ação de uma substância finita sobre outra consiste unicamente no aumento do grau de sua expressão, juntamente com a diminuição da expressão da outra..." "Assim, uma substância que tenha uma extensão infinita, enquanto exprime tudo, torna-se limitada pelo modo mais ou menos perfeito como o exprime. É portanto nesse sentido que podemos pensar [em um sentido não metafísico] as substâncias como impedindo e limitando umas às outras, e consequentemente é nesse sentido que podemos dizer que elas agem umas sobre as outras, sendo obrigadas, por assim dizer, a se adaptarem umas às outras." 
vas? Como seria possível a existência de relações entre criaturas perfeitas? ? $^{31}$ Essas mônadas perfeitas não seriam apenas sem janelas; elas teriam que ser cegas, surdas e mudas.

Em suma, o mundo mais perfeito possível, o mundo que realiza a maior quantidade de essência, não poderia ser composto exclusivamente de substâncias perfeitas. Uma multiplicidade de substâncias perfeitas seria, na verdade, uma única substância perfeita - e a única substância absolutamente perfeita é Deus. Para criar o melhor mundo, para produzir o máximo de essência, complexidade e perfeição, Deus terá que dar existência à maior variedade possível de substâncias, cada qual realizando e desenvolvendo um grau próprio de perfeição ou essência. Em outras palavras, a perfeição do mundo como um todo supõe sua diversidade interna, e a diversidade, por sua vez, exige a imperfeição, maior ou menor, das substâncias criadas ${ }^{32}$.

Aliás, ainda que fosse possível, um mundo composto exclusivamente de substâncias perfeitas, um mundo de deuses, seria na verdade menos desejável que o nosso. Ao longo de alguns parágrafos da segunda parte da Teodicéia (197 a 203), Leibniz faz algumas observações sobre o livro do teólogo católico François Diroys, seu contemporâneo, intitulado Preuves et préjugés pour la religion chrétienne et catholique contre les fausses religions et l'athéisme (1683). Em seu livro, Diroys afirma que, se é verdade que Deus produz sempre o melhor, então ele deveria produzir um mundo composto exclusivamente de deuses. Leibniz pondera que essa visão é parcial, e que Diroys não considera a ordem e a ligação das coisas.

Se cada substância considerada isoladamente fosse perfeita, elas seriam todas semelhantes - o que não é conveniente nem possível. Se fossem deuses, não teria sido possível produzi-las. O melhor sistema das coisas, portanto, não conterá deuses; será sempre um sistema de corpos, quer dizer de coisas dispostas segundo os lugares e os tempos, e de almas que representam e apercebem os corpos, e segundo as quais os corpos são em boa parte governados (Théodicée, 200)

Que Deus produza o melhor mundo possível, o mundo mais perfeito possível, não quer dizer que os seres que compõem esse mundo, considerados isoladamente, sejam perfeitos. A perfeição do ato divino da criação está

31 Cf. ainda Monadologie, 50: "Uma criatura é mais perfeita que outra se nela encontramos a razão a priori do que se passa na outra; e é por isso que dizemos que ela age sobre a outra." E \$ 56: "Ora, essa ligação ou acomodação de todas as coisas criadas a cada uma e de cada uma a todas as outras faz com que cada substância simples tenha relações que exprimem todas as outras e consequentemente seja um perpétuo espelho vivo do universo." Ver tb. \$ 52.

32 Cf. Moreau, q. cit. p. 188, e Rutherford, q. cit. pp. 25-26. Cf. ainda Da origem radical das coisas, p. 92: além dos argumentos acima, que explicam por que para Leibniz o mundo mais perfeito não pode ser um mundo formado de substâncias perfeitas, podemos acrescentar um outro: a divisibilidade infinita do contínuo, que faz com que sempre haja ainda outros elementos a serem desenvolvidos em cada substância. 
justamente na produção do maior número e variedade possível de efeitos a partir das causas ou meios mais simples. É essa regra que orienta a escolha divina. Leibniz insiste repetidamente, na Teodicéia como em vários outros textos, na importância desses dois pontos: que o sentido, a beleza e a harmonia das partes só se mostram pela consideração da totalidade, e que o sentido e a harmonia dessa totalidade estão, não na monotonia, mas na infinita diversidade de suas partes infinitas, juntamente com a simplicidade dos meios empregados para sua produção.

Um dos melhores exemplos desse pensamento está em suas respostas (§§ 116-ss da Teodicéia) às dezenove máximas filosóficas que Bayle apresenta contra seu sistema e contra sua explicação da origem do mal físico e moral. Respondendo uma a uma a essas máximas, Leibniz vai repetindo: querer, como Bayle, que não houvesse males no mundo, querer que não houvesse vícios nem crimes, pensar que Deus, por sua onipotência e onisciência, poderia e deveria ser capaz de criar um mundo em que os homens fossem todos bons, virtuosos e felizes - isso é separar as partes do todo, e deixar-se guiar pela falsa máxima de que a felicidade das criaturas racionais é o único objetivo de Deus (idem, 120). Nós vemos um pequeno fragmento, Deus vê a ligação de todos os fragmentos em sua obra completa. Nós somos uma parte, uma parte importante, mas Deus não despreza nenhuma criatura, e nenhum fio de cabelo de nenhuma criatura (cf. Théodicée, Préface, p. 30). Por isso nosso mundo não poderia ter sido diferente, nem melhor. Por isso o mal era inevitável.

A insistência de Bayle, ao longo de suas objeções, em bater sempre na mesma tecla, obrigando Leibniz a dar sempre a mesma resposta com pequenas variações, gera, já na resposta à $9^{a}$ máxima (Théodicée, 124), uma espécie de desabafo. Leibniz reage à repetitividade e falta de inventividade de seu opositor, mas no fundo sua irritação é apenas reflexo de uma reação conceitual, contra a repetitividade e mesmo contra a falta de sentido do mundo que Bayle, como muitos outros, crê ser o melhor. A indiferença, a simetria, a ausência de males, desequilíbrios e dissonâncias na harmonia representariam (caso fossem possíveis) uma perda de perfeição no mundo criado, além de diminuir nossa capacidade de saborear todos os bens existentes. E tudo seria, enfim, muito entediante. A citação é um pouco longa, mas vale a pena, porque condensa boa parte do que dissemos. Eu termino com ela:

\footnotetext{
"Ainda não estou nem na metade das 19 máximas, e já estou cansado de refutar e responder sempre a mesma coisa [...] Se só houvesse virtude, se só houvesse criaturas racionais, haveria menos bem. Midas ficou menos rico quando só tinha ouro. Além disso, a sabedoria deve variar. Multiplicar unicamente a mesma coisa, por mais nobre que ela seja, seria uma superfluidade, seria uma pobreza. Ter mil Virgí-
} 
lios bem encadernados em sua biblioteca, cantar sempre as árias da ópera de Cadmos e Hermione, quebrar todas as porcelanas para só possuir taças de ouro, ter apenas botões de diamante, não comer senão perdizes, não beber senão vinho da Hungria ou de Shiras - chamaríamos a isso de razão? A natureza precisou de animais, de plantas, de corpos inanimados; há nessas criaturas não racionais maravilhas que servem para exercer a razão. Que faria uma criatura inteligente se não houvesse coisas não inteligentes? Em que pensaria ela, se não houvesse nem movimento, nem matéria, nem sentidos? Se ela só tivesse pensamentos distintos, seria um deus, sua sabedoria não teria limites (...) A partir do momento em que há uma mistura de pensamentos confusos, eis os sentidos, eis a matéria. Pois esses pensamentos confusos vêm da relação de todas as coisas entre si, segundo a duração e a extensão. É por isso que em minha filosofia não há criatura racional sem um corpo orgânico, e não há espírito criado que seja inteiramente desvinculado da matéria. Mas esses corpos orgânicos não diferem menos em perfeição que os espíritos a que pertencem." (Théodicée, 124)

\section{Bibliografia}

\section{1. obras de Leibniz:}

Gerhardt, C.I. Die philosophischen Schriften von Gottfried Wilhelm Leibniz. Hildesheim: Georg Olms, 1978.

Grua, G. G.W. Leibniz: Textes inédits. Paris: PUF, 1998.

Loemker, L.E. Gottfried Wilhelm Leibniz: philosophical papers and letters. Dordrecht: Kluwer, 1989.

Rauzy, J.-B. Recherches Générales sur l'analyse des notions et des vérités: 24 thèses métaphysiques et autres textes logiques et métaphysiques. Paris: PUF, 1998.

Schrecker, P. G.W. Leibniz: opuscules philosophiques choisis. Paris: Vrin, 1978.

Correspondance Leibniz-Clarke (ed. A. Robinet). Paris: PUF, 1957.

Essais de Théodicée. Paris: Garnier-Flammarion, 1969.

Discours de Métaphysique et Correspondance avec Arnaud (ed. G. Le Roy). Paris: J. Vrin, 1988.

Nouveaux Essais sur l'Entendement Humain. Paris: Garnier-Flammarion, 1990.

La Monadologie (ed. E. Boutroux). Paris: Delagrave, 1998.

De l'Horizon de la Doctrine Humaine: Apokatastasis pantwn (La Restitution Universelle) (org. M. Fichant). Paris: J. Vrin, 1991.

\section{2. outras fontes:}

Bayle, P. Dictionnaire historique et critique, Paris: Desoer, 1820.

Cicero, Traité du Destin, in Les Stö̈ciens. 1983 [1962]. Les Stoüciens (Bibliothèque de la Pléiade, trad. E. Bréhier). Paris: Gallimard, 1983.

Descartes, R. Euvres et Lettres (Bibliothèque de la Pléiade). Paris: Gallimard, 1953. Oeuvres Philosophiques, tome III (1643-1650). Paris: Classiques Garnier, 1998.

Montaigne. Essais, in Oeuvres Complètes (Bibliothèque de la Pléiade). Paris: Gallimard, 1962.

Spinoza. Euvres Complètes. (Bibl. de la Pléiade). Paris: Gallimard, 1954. 


\section{3. estudos sobre Leibniz e outros:}

Adams, R.M. Leibniz: Determinist, Theist, Idealist. Oxford: Oxford University Press, 1998 [1994] .

Breger, H. "Symmetry in Leibnizean Physics." In The Leibniz Renaissance International Workshop, Firenze, 2-5 giugno 1986. Centro fiorentino di storia e filosofia della scienza. Florença: Leo S. Olschki, 1989.

Fichant, M. Postface: "Plus Ultra". In De l'Horizon de la Doctrine Humaine: Apokatastasis pantwn (La Restitution Universelle). Paris: J. Vrin, 1991, pp. 125-210.

Lopes dos Santos, L.H. "Leibniz e a questão dos futuros contingentes". Analytica, 3, 1998: 91-121.

Moreau, J. L'Univers Leibnizien. Hildesheim: Georg Olms, 1987.

Pinheiro, U. "Contingência e análise infinita em Leibniz". Kriterion, neste volume.

Rauzy, J.-B. "Quid sit natura prius? La conception leibnizienne de l'ordre.” Revue de Métaphysique et de Morale, 1/jan-mar 1995: 31-48.

Rescher, N. "Choice without preference", in Kant Studien 21 (1959-1960): 142-175.

Rutherford, D. Leibniz and the Rational Order of Nature. Cambridge: Cambridge University Press, 1998.

Serres, M. Le Système de Leibniz et ses Modèles Mathématiques. Paris: PUF, 1990.

Weyl, H. Symmetry. Princeton: Princeton University Press, 1980. 